\title{
Effectiveness of imatinib mesylate over etoposide in the treatment of sensitive and resistant chronic myeloid leukaemia cells in vitro
}

\author{
ROSLINA HUSAINI ${ }^{1}$, MUNIRAH AHMAD ${ }^{2}$ and ZUBAIDAH ZAKARIA ${ }^{1}$ \\ ${ }^{1}$ Haematology Unit and ${ }^{2}$ Molecular Pathology Unit, Cancer Research Centre, \\ Institute for Medical Research, Jalan Pahang, 50588 Kuala Lumpur, Malaysia
}

Received December 14, 2015; Accepted December 23, 2016

DOI: $10.3892 /$ etm.2017.4443

\begin{abstract}
Chronic myeloid leukaemia (CML) is a form of leukaemia derived from the myeloid cell lineage. Imatinib mesylate, the breakpoint cluster region-abelson murine leukeamia kinase inhibitor, is a specific reagent used in the clinical treatment of CML. The DNA topoisomerase II inhibitor, etoposide, is also employed as a therapeutic, though it is used to a lesser extent. The present study aims to evaluate the effects of CML-targeted therapy, utilising imatinib mesylate and etoposide in the in vitro treatment of parental sensitive and adriamycin-resistant CML in the K562 and K562/ADM cell lines, respectively. Preliminary work involved the screening of multidrug resistant (MDR) gene expression, including MDR1, MRP1 and B-cell lymphoma 2 (BCL-2) at the mRNA levels. The sensitive and resistant CML cell lines expressed the MRP1 gene, though the sensitive K562 cells expressed low, almost undetectable levels of MDR1 and BCL-2 genes relative to the K562/ADM cells. Following treatment with imatinib mesylate or etoposide, the $\mathrm{IC}_{50}$ for imatinib mesylate did not differ between the sensitive and resistant cell lines $(0.492 \pm 0.024$ and $0.378 \pm 0.029$, respectively), indicating that imatinib mesylate is effective in the treatment of CML regardless of cell chemosensitivity. However, the $\mathrm{IC}_{50}$ for etoposide in sensitive K562 cells was markedly lower than that of K562/ADM cells $(50.6 \pm 16.5$ and $194 \pm 8.46 \mu \mathrm{M}$, respectively), suggesting that the higher expression levels of MDR1 and/or BCL-2 mRNA in resistant cells may be partially responsible for this effect. This is supported by terminal deoxynucleotidyl transferase dUTP nick-end labeling data, whereby a higher percentage of apoptotic cells were found in the sensitive and resistant K562 cells treated with imatinib mesylate $(29.3 \pm 0.2$ and $31.9 \pm 16.7 \%$, respectively), whereas etoposide caused significant apoptosis of sensitive K562 cells
\end{abstract}

Correspondence to: Ms. Roslina Husaini, Haematology Unit, Cancer Research Centre, Institute for Medical Research, Jalan Pahang, 50588 Kuala Lumpur, Malaysia

E-mail: roslinahusaini@hotmail.com

Key words: chronic myeloid leukaemia, targeted therapy, apoptosis, multidrug resistance, RNA interference, short interfering RNA
$(18.3 \pm 8.35 \%)$ relative to K562/ADM cells (5.17 $\pm 3.3 \%)$. In addition, the MDR genes in K562/ADM cells were knocked down by short interfering RNAs. The percentage knockdowns were $15.4 \%$ for MRP1, $17.8 \%$ for MDR and $30.7 \%$ for BCL-2, which resulted in a non-significant difference in the half maximal inhibitory concentration value of K562/ADM cells relative to K562 cells upon treatment with etoposide.

\section{Introduction}

Chronic myeloid leukaemia (CML) is a form of leukaemia in which large numbers of abnormal and non-functional myeloid cells, particularly granulocytes, are uncontrollably produced in the bone marrow. Thus, CML is of myeloid origin, and develops and displays symptoms gradually. According to the National Cancer Institute in the USA, CML is more prevalent amongst adult males, and rarely occurs in children $(1,2)$. The majority of CML patients are positive for the abnormal the Philadelphia chromosome $(\mathrm{Ph})$, formed due to a reciprocal translocation occuring between chromosome 9 and $22[\mathrm{t}(9 ; 22)$ (q34;q11)], resulting in the fusion of the breakpoint cluster region $(\mathrm{BCR})$ and abelson murine leukaemia $(\mathrm{ABL})$ genes $(3,4)$. The BCR-ABL fusion product is a chimeric BCR-ABL oncoprotein with constitutive tyrosine kinase activity, enabling it to activate multiple signalling pathways. This leads to the initiation and maintenance of CML transformation, with enhanced cell proliferation, growth rate and survival (5-7).

Conventional chemotherapy is widely used to treat CML. Most chemotherapeutic drugs act by inducing apoptotic cell death in cancer cells undergoing high rates of proliferation, though the drugs also target highly proliferative normal cells. Therefore, the use of targeted therapy to treat CML is increasing, including the use of imatinib mesylate, which specifically inhibits the BCR-ABL fusion tyrosine kinase (8-11). However, a major obstacle responsible for cancer treatment failure is multidrug resistance (MDR). MDR is defined as the resistance of tumour cells to cytotoxic substances and occurs at diagnosis (primary resistance), or is acquired following treatment (secondary resistance) (12-17). In MDR, tumour cells exhibit resistance to different reagents, each with different chemical structures and targeting mechanisms (13). The mechanisms that provide tumour cells with MDR are divided into four groups, as follows: i) Decreased accumulation of intracellular drugs; ii) decreased drug activation or increased detoxification 
of the drugs intracellularly via the glutathione system; iii) alterations in the drug targets or enhanced repair of the damaged target; and iv) alterations in the genes and proteins that regulate apoptosis and the survival of tumour cells, particularly alterations occurring in the tumour suppressor protein $\mathrm{p} 53$ and the anti-apoptotic protein B-cell lymphoma 2 (BCL-2) $(13,18)$ The MDR mechanisms may occur in the same cells and are potentially interconnected.

It is considered that the resistance of CML cells to apoptosis, induced by conventional chemotherapeutic drugs, is in part due to a combined presence of the BCR-ABL protein, the mutant p53 protein $(6,13,18-20)$, the expression of MDR genes, including the MDR1 gene product, P-glycoprotein (P-gp), and MDR-related protein 1 (MRP1) (21-23) and over-expression of BCL-2 family members $(13,18,24)$.

As a mechanism of MDR, decreased intracellular drug accumulation is attributed to the overexpression and activation of adenosine triphosphate-binding cassette transmembrane drug transporters, namely P-gp (with apparent MW of $170 \mathrm{kDa}$ ) and MRP (with apparent MW of $190 \mathrm{kDa}$ ), which act by increasing the efflux of drugs from cells $(21,23,25,26)$. Acquired MDR observed in different types of cancer, including ovarian cancer (27), myeloma/lymphoma (28), breast cancer (29), neuroblastoma (30) and esophageal cancer (31), is primarily due to increased P-gp overexpression following tumour therapy (32). A P-gp-MDR positive state has been revealed in haematological malignancies, and it has been found to indicate a poor prognosis in these types of cancer (33). However, the mechanism of MRP action with regard to P-gp remains unknown.

The anti-apoptotic BCL-2 family is known to inhibit apoptosis and it is repressed by the wild-type p53 protein in response to genotoxic stress. The presence of BCL-2 proteins contributes to a poor efficacy of chemotherapy and it has been suggested that a high BCL-2/BCL-2-related X protein (BAX) ratio induces in vitro cellular resistance to drug-induced apoptosis (34). BAX acts as a pro-apoptotic protein that induces apoptosis, and low levels of BAX expression and/or its inactivation results in a high ratio of BCL-2/BAX, leading to inhibition of apoptosis $(35,36)$. Therefore, BCL-2 overexpression may indicate a poor prognosis for certain tumours, particularly for haematological malignancies, such as lymphoid and myeloid leukemia.

The development of novel targeted therapies, including antisense oligonucleotides, small molecule inhibitors and specific monoclonal antibodies, may facilitate in overcoming MDR in human malignancies. One such method is RNAi technology, in which small interfering RNA (siRNA) and short hairpin RNA are used to silence specific gene expression by targeting and degrading the corresponding mRNA (37-39). There is evidence for this occuring in a study by Caplen et al (40), in which double stranded siRNA 21-23 nucleotides long was able to silence gene expression in mammalian cells. In the present study, RNAi with siRNA was applied in order to silence genes responsible for MDR in CML cells, including MDR1, MRP1 and BCL-2. This was followed by treatment with an existing chemotherapeutic drug, to determine whether the siRNA-targeted gene knockdowns were able to restore the sensitivity of the CML cell lines to chemotherapy. A previous study by Wu et al (41) found that MDR1 siRNA in a breast cancer cell line was able to suppress the MDR1 gene, resulting in the restored sensitivity of these cells to chemotherapeutic drugs. Therefore, the ability of siRNA to specifically and effectively inhibit the expression of genes in mammalian cells offers potential as a gene-targeting therapy to treat cancer $(38,39)$.

In the present study, the effectiveness of the targeted drug imatinib mesylate compared with the conventional chemotherapeutic drug etoposide was investigated. Specifically, MTS and Terminal deoxynucleotidyl transferase dUTP nick-end labeling (TUNEL) assays were used to measure the viability of parental sensitive and adriamycin-resistant CML model cell lines K562 and K562/ADM, respectively, following drug treatment. In addition, RNAi of MDR genes was employed in order to evaluate the mechanisms of multidrug resistance in CML.

\section{Materials and methods}

Cell culture. In the present study, the CML cell lines parental sensitive K562 and adriamycin-resistant K562/ADM, were purchased from American Type Culture Collection (Manassas, VA, USA) and RIKEN BioSource Centre (Tsukuba, Japan), respectively. K562/ADM cells were generated according to a previously described method (42). The cells were propagated in complete RPMI-1640 medium supplemented with $10 \%$ fetal calf serum (Invitrogen; Thermo Fisher Scientific, Inc., Waltham, MA, USA), $100 \mathrm{U} / \mathrm{ml}$ penicillin and $100 \mu \mathrm{g} / \mathrm{ml}$ streptomycin (Invitrogen; Thermo Fisher Scientific, Inc.), and grown in a $5 \% \mathrm{CO}_{2}$ humidified incubator at $37^{\circ} \mathrm{C}$ until $70 \%$ confluence was reached.

Semi-quantitative reverse transcription-polymerase chain reaction $(R T-P C R)$ of $M D R$ genes. The expression of the selected MDR genes (MDR1, MRP1 and BCL-2) in the CML cell lines was analyzed by RT-PCR. RNA from each cell line was extracted using a Qiagen RNeasy extraction kit (Qiagen GmbH, Hilden, Germany), following the manufacturer's protocol. RNA was quantified using a Nanodrop Spectrophotometer (Thermo Fisher Scientific, Inc.), then $1 \mu \mathrm{l}$ RNA was run alongside an RNA ladder ( $3 \mu \mathrm{g}$; Invitrogen; Thermo Fisher Scientific, Inc.) on a $1 \%$ agarose gel incorporated with $0.5 \mu \mathrm{g} / \mathrm{ml}$ ethidium bromide (Sigma-Aldrich; Merck $\mathrm{KgA}$, Darmstadt, Germany) to verify RNA integrity. A total of $1 \mu \mathrm{g}$ RNA was reverse transcribed to obtain cDNA using a SuperScript ${ }^{\mathrm{TM}}$ III Synthesis System for RT-PCR (Invitrogen; Thermo Fisher Scientific, Inc.), according to the manufacturer's protocol. cDNA products were quantified using a Nanodrop Spectrophotometer, then subjected to PCR in order to to check the expression levels of mRNA for the selected MDR genes. An i-PCR 5X Master Mix (i-DNA Biotechnology, Pte., Ltd., Singapore) containing Taq DNA Polymerase (0.1 unit/ $\mu \mathrm{l})$, $1.5 \mathrm{mM}$ magnesium chloride and $1 \mathrm{mM}$ dNTP's (dATP, dCTP, dGTP, dTTP) was employed for PCR reactions. GAPDH was used as a loading control for normalization. The following forward and reverse primers were used: MDR1; forward, 5'-CCCATCATTGCAATAGCAGG-3' and reverse, 5'-GTT CAAACTTCTGCTCCTGA-3', MRP1; forward, 5'-GGACCT GGACTTCGTTCTCA-3' and reverse, 5'-CGTCCAGACTTC CTTCATCCG-3' (43), BCL-2; forward, 5'-ACTTGTGGC 
CCAGATAGGCACCCAG-3' and reverse, 5'-CGACTTCGC CGAGATGTCCAGCCAG-3' (44) and GAPDH; forward, 5'-TGACCTTGCCCACAGCCTTG-3' and reverse, 5'-CAT CACCATCTTCCAGGAGCG-3'. The cycling conditions for the genes were $94^{\circ} \mathrm{C}$ for $5 \mathrm{~min}, 35$ cycles of $94^{\circ} \mathrm{C}$ for $30 \mathrm{sec}$, annealing temperatures (Ta) for $30 \mathrm{sec}$ (Ta's for MDR1, MRP1, BCL-2 and GAPDH were $53.4^{\circ} \mathrm{C}, 57.4^{\circ} \mathrm{C}, 64.5^{\circ} \mathrm{C}$ and $59.5^{\circ} \mathrm{C}$, respectively), $72^{\circ} \mathrm{C}$ for $30 \mathrm{sec}$, followed by 1 cycle at $72^{\circ} \mathrm{C}$ for $5 \mathrm{~min}$. The RT-PCR products ( $5 \mu \mathrm{l} / \mathrm{lane})$ were run on alongside a 100 bp DNA ladder $(0.5 \mu \mathrm{g}$; Invitrogen; Thermo Fisher Scientific, Inc.) on a $1 \%$ agarose gel (Invitrogen; Thermo Fisher Scientific, Inc.) incorporated with $0.5 \mu \mathrm{g} / \mathrm{ml}$ ethidium bromide (Sigma-Aldrich; Merck KgaA) and photographed using a gel documentation system. The size of the RT-PCR products for MDR1, MRP1, BCL-2 and GAPDH were 157, 252,385 and $443 \mathrm{bp}$, respectively. A negative control (no cDNA template) and RT control (no reverse transcription) were also included in the aforementioned reactions. Assessment of MDR gene expression levels in both K562 and K562/ADM cells was conducted only once.

siRNA transfection. siRNAs for MDR1, MRP1 and BCL-2, and non-coding siRNA (negative control), were designed and purchased from GE Dharmacon (Thermo Fisher Scientific, Inc.). Cells were seeded in 6-well plates at $1 \times 10^{6}$ cells $/ \mathrm{ml}$ in complete RPMI-1640 medium (Invitrogen; Thermo Fisher Scientific, Inc.) and transfected with individual siRNAs at a siRNA: DharmaFect ${ }^{\circledR}$ siRNA Transfection Reagent (Thermo Fisher Scientific, Inc.) ratio of $25 \mu \mathrm{M}: 2 \mu \mathrm{l}$. The cells were incubated in a $5 \% \mathrm{CO}_{2}$ incubator at $37^{\circ} \mathrm{C}$ for $48 \mathrm{~h}$. The transfected cells were then harvested and their RNA extracted using the Qiagen RNeasy extraction kit. Reverse transcription was performed to obtain cDNA using a SuperScript ${ }^{\mathrm{TM}}$ III Synthesis System for RT-PCR, according to the manufacturer's protocol. The cDNA was used for qPCR to determine the effects of RNA silencing on MDR gene expression levels.

RT-quantitative PCR (RT-qPCR) of samples post-siRNA transfection. The cDNA samples (100 ng) were used in qPCR to determine the effects of siRNA knockdown on the MDR genes. A LightCycler ${ }^{\circledR} 480$ SYBR Green I Master (Roche Diagnostics, Basel, Switzerland) containing a specific double strand (ds) DNA binding agent SYBR Green I dye was used for quantification of the RT-PCR products, according to the manufacturer's protocol (45). The primers used for each gene were as in the RT-PCR protocol stated above, with the exception of GAPDH, whereby the forward and reverse primers were: Forward, 5'-CCAAAATCAAGTGGGGCGATG-3' and reverse, 5'-AAAGGTGGAGGAGTGGGTGTCG-3' (46). The assays were performed in a 96-well plate that was subsequently run through the Roche LightCycler ${ }^{\circledR} 480$. The PCR conditions were a pre-incubation step at $95^{\circ} \mathrm{C}$ for $5 \mathrm{~min}$, then 45 cycles of amplification, including denaturation at $95^{\circ} \mathrm{C}$ for $10 \mathrm{sec}$, annealing at $60^{\circ} \mathrm{C}$ for $15 \mathrm{sec}$ and extension at $72^{\circ} \mathrm{C}$ for $10 \mathrm{sec}$, followed by melting curve analysis to confirm gene specific products. Quantification Cycle $\left(\mathrm{C}_{\mathrm{q}}\right)$ values were compared with those of the standard or calibration curves using advanced relative quantification analysis via the Efficiency Method (47). Gene expression was normalised with expression of the loading control GAPDH. The expression ratio of each MDR gene in cells treated with MDR gene siRNAs relative to cells treated with negative control siRNA was calculated, then converted to a knockdown percentage. Three independent experiments were performed.

MTS assay. The cell lines were seeded at $2.5 \times 10^{5}$ cells $/ \mathrm{ml}$ in complete RPMI 1640 medium (Invitrogen; Thermo Fisher Scientific, Inc.) in a 96-well plate. The cells were treated with imatinib mesylate (Cayman Chemical Company, Ann Arbor, MI, USA) and etoposide (Sigma-Aldrich; Merck $\mathrm{KgaA})$ at varying concentrations (0-50 $\mu \mathrm{M}$ imatinib mesylate and $0-500 \mu \mathrm{M}$ etoposide) in a $5 \% \mathrm{CO}_{2}$ incubator at $37^{\circ} \mathrm{C}$ for $48 \mathrm{~h}$. Cells not treated with either drug were used as controls for comparison with treated cells. The drug treatments were stopped by adding $20 \mu \mathrm{l}$ MTS solution containing a tetrazolium compound [3-(4,5-dimethylthiazol-2-yl)-5-(3-carboxymethoxy phenyl)-2-(4-sulfophenyl)-2H-tetrazolium inner salt; MTS] and an electron coupling reagent (phenazine ethosulfate; CellTiter $96^{\circledR}$ Aqueous One Solution Cell Proliferation Assay; Promega Corporation, Madison, WI, USA), then incubated in a $5 \% \mathrm{CO}_{2}$ incubator at $37^{\circ} \mathrm{C}$ for $4 \mathrm{~h}$ in the dark. The cells were then read with a universal multi-well plate reader at $570 \mathrm{~nm}$ using a reference wavelength of $630 \mathrm{~nm}$. The drug concentration at 50\% inhibition $\left(\mathrm{IC}_{50}\right)$ was determined by plotting cell viability (\%) vs. drug concentration $(\mu \mathrm{M})$. Three independent experiments were performed.

TUNEL assay. The cell lines were seeded at $1 \times 10^{6}$ cells $/ \mathrm{ml}$ in complete RPMI-1640 medium (Invitrogen; Thermo Fisher Scientific, Inc.) in 6-well plates, followed by treatment with $0.5 \mu \mathrm{M}$ imatinib mesylate or $50 \mu \mathrm{M}$ etoposide for 24 and $48 \mathrm{~h}$. Untreated cells were used as negative controls. A TUNEL assay kit (DeadEnd ${ }^{\mathrm{TM}}$ Fluorometric TUNEL System; Promega Corporation) was used to detect apoptotic cells. The cells were harvested and seeded onto poly-L-lysine (Sigma-Aldrich: Merck KgaA) glass slides, according to the manufacturer's instructions. The cells were then fixed by immersing slides in $4 \%$ formaldehyde (Sigma-Aldrich; Merck KgaA) in PBS for $25 \mathrm{~min}$ at $4^{\circ} \mathrm{C}$, followed by a wash in PBS for $5 \mathrm{~min}$. The cells were then permeabilized in $0.2 \%$ Triton X-100 (Sigma-Aldrich; Merck KgaA) in PBS for 5 min, followed by washing in PBS for $5 \mathrm{~min}$. The cells were subsequently equilibrated in Equilibration Buffer (DeadEnd ${ }^{\mathrm{TM}}$ Fluorometric TUNEL System; Promega Corporation) at room temperature for 5-10 min. Following this, a Recombinant Terminal Deoxynucleotidyl Transferase reaction mix (DeadEnd ${ }^{\mathrm{TM}}$ Fluorometric TUNEL System; Promega Corporation) was added to the cells and cells were covered with plastic coverslips. Slides were then incubated in a humidified chamber in the dark for $60 \mathrm{~min}$ at $37^{\circ} \mathrm{C}$. The reaction was stopped by immersing the slides in $2 \mathrm{X}$ saline sodium citrate for $15 \mathrm{~min}$, followed by $3 \times 5 \mathrm{~min}$ washes in PBS. Slides were mounted and simultaneously counterstained with ProLong ${ }^{\circledR}$ Gold antifade reagent supplemented with DAPI nuclear stain (Invitrogen; Thermo Fisher Scientific, Inc.) for $24 \mathrm{~h}$ at room temperature in the dark. The apoptotic cells were visualised and counted with a Nikon Fluorescence Microscope using Nikon Imaging Software Elements, with green indicating apoptotic cells and blue indicating cell nuclei. The percentages of apoptotic cells were determined by counting three fields of $\sim 200$ cells/field in $\geq 2$ independent experiments. 
Table I. $\mathrm{IC}_{50}$ values for $\mathrm{K} 562$ and $\mathrm{K} 562 / \mathrm{ADM}$ cells treated with imatinib mesylate $(0-50 \mu \mathrm{M})$ and etoposide $(0-500 \mu \mathrm{M})$ for $48 \mathrm{~h}$.

\begin{tabular}{lcc}
\hline Drug & $\mathrm{K} 562$ cell & $\mathrm{K} 562 / \mathrm{ADM}$ cell \\
$\mathrm{IC}_{50}(\mu \mathrm{M})$
\end{tabular}

There was no significant difference between the $\mathrm{IC}_{50}$ values of the K562 and K562/ADM cell lines treated with imatinib mesylate. There was a significant difference between the $\mathrm{IC}_{50}$ values of the cell lines treated with etoposide. Values represent the means \pm standard deviation. ${ }^{\mathrm{a}} \mathrm{P}<0.05$ vs. etoposide-treated $\mathrm{K} 562 / \mathrm{ADM}$ cells; ${ }^{\text {ns }} \mathrm{P}>0.05$ vs. imatinib mesylate-treated $\mathrm{K} 562 / \mathrm{ADM}$ cells. $\mathrm{IC}_{50}$, half maximal inhibitory concentration; ns, not significant; K562, parental sensitive chronic myeloid leukaemia cell line; K562/ADM, adriamycin-resistant chronic myeloid leukaemia cell line.

Statistical analysis. Data are presentated as the mean \pm standard deviation. Differences in gene expression were analyzed by one-way analysis of variance and the Bonferroni post-hoc test using GraphPad Prism 5.0 (GraphPad software, Inc., La Jolla, CA, USA). Results were considered to be statistically significant when $\mathrm{P}<0.05$.

\section{Results}

Gene expression of MDR1 and BCL-2 is higher in the adriamycin-resistant CML cell line. Parental sensitive K562 and adriamycin-resistant K562/ADM cell lines were subjected to semi-quantitative RT-PCR to analyze the expression of the MDR1, MRP1 and BCL-2 genes. The sensitive and resistant K562 cells exhibited similar levels of MRP1 mRNA expression (Fig. 1). The RT-PCR products for MDR1 and BCL-2 indicated that K562/ADM cells expressed higher levels of MDR1 mRNA (4.5-fold increase) and BCL-2 mRNA (6-fold increase) relative to parental sensitive K562 cells (Fig. 1). As BCL-2 is an anti-apoptotic gene, the higher level of BCL-2 mRNA detected in K562/ADM cells was expected to inhibit apoptosis relative to parental sensitive K562 cells. Therefore, subsequent treatment of the cell lines with chemotherapeutic agents were expected to induce a greater apoptotic rate in the parental sensitive K562 cells.

Parental sensitive and adriamycin-resistant $K 562$ cells have greater sensitivity to imatinib mesylate relative to etoposide. In order to determine the sensitivity of the K562 cell lines to imatinib mesylate and etoposide, cells were treated with varying concentrations of each drug for $48 \mathrm{~h}$, followed by an MTS assay. The survival curves were plotted and $\mathrm{IC}_{50}$ values were derived from the curves (Fig. 2 and Table I). For the imatinib mesylate treatments, no significant difference was observed between the $\mathrm{IC}_{50}$ values of the sensitive and resistant $\mathrm{K} 562$ cell lines, indicating that imatinib mesylate decreased cell viability in each cell line, regardless of the higher MDR1 and BCL-2 mRNA levels in $\mathrm{K} 562 / \mathrm{ADM}$ cells. However, the $\mathrm{IC}_{50}$ for etoposide was significantly lower in parental sensitive K562 cells relative to
A

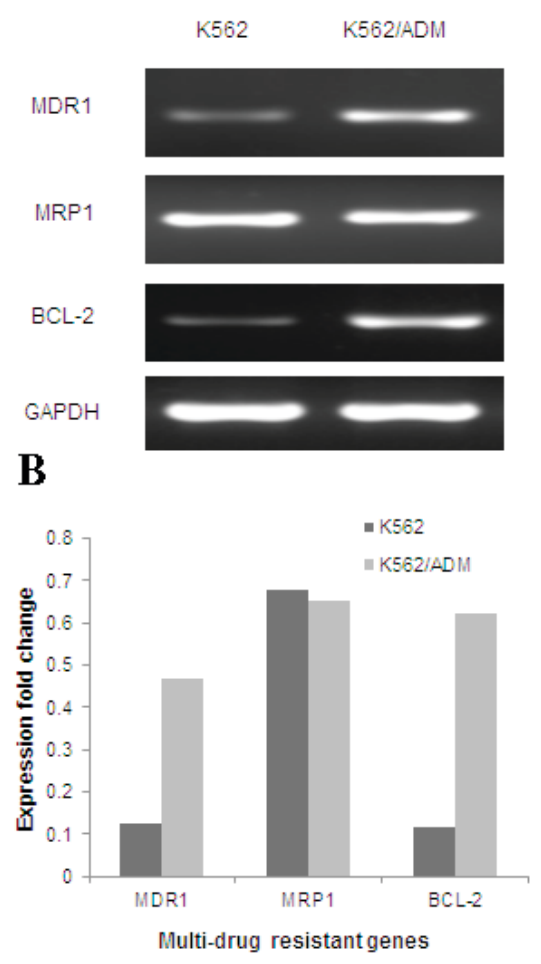

Figure 1. Semi-quantitative reverse transcription-polymerase chain reaction products for MDR1, MRP1, BCL-2 and GAPDH. (A) Similar levels of MRP1 mRNA were observed in the K562 and K562/ADM cells. Low levels of MDR1 and BCL-2 mRNA were detected in the K562 cells relative to the K562/ADM cells. (B) The fold-change of MDR gene mRNA levels normalised to the internal control gene GAPDH, as quantified by ImageJ. Relative to KD562 cells, an approximate 4.5-fold and 6-fold increase in MDR1 and BCL-2 gene expression was observed in K562/ADM cells, respectively. MDR1, multidrug resistance 1; MRP1, MDR-associated protein 1; BCL-2, B-cell lymphoma 2; K562, parental sensitive chronic myeloid leukaemia cell line; K562/ADM, adriamycin-resistant chronic myeloid leukaemia cell line.

K562/ADM cells $(50.6 \pm 16.5$ and $194 \pm 8.46 \mu \mathrm{M}$, respectively; $\mathrm{P}<0.05$ ), indicating that $\mathrm{K} 562 / \mathrm{ADM}$ cells were resistant to etoposide.

Gene knockdown of MDR-1, MRPI and BCL-2 has little effect on the response of K562/ADM cells to etoposide. In an attempt to sensitise K562/ADM cells to etoposide, the MDR genes of interest were silenced by RNAi. Following several rounds of optimisation, it was found that the percentage gene knockdowns of MDR1 (17.8\%), MRP1 (15.4\%) and BCL-2 (30.7\%) did not differ significantly (Fig. 3A). In addition, the K562/ADM growth curves for each gene knockdown were similar, indicating that the extent to which the genes were knocked down did not affect cell growth (Fig. 3B). The low level of gene knockdown did not significantly reduce the $\mathrm{IC}_{50}$ of $\mathrm{K} 562 / \mathrm{ADM}$ resistant cells treated with etoposide relative to K562/ADM cells transfected with negative control siRNA (Table II). Furthermore, the $\mathrm{IC}_{50}$ of parental sensitive K562 treated with etoposide, as a positive control, was significantly lower than that observed for the siRNA-treated K562/ADM cells ( $\mathrm{P}<0.05)$, including the negative control siRNA transfectants (Table II).

Imatinib mesylate induces a greater apoptotic rate in $K 562$ cells relative to etoposide. A TUNEL assay was performed to 
Table II. $\mathrm{IC}_{50}$ values for K562/ADM cells with siRNA knockdown of the MDR genes, MDR1, MRP1 and BCL-2, followed by treatment with etoposide. ${ }^{\mathrm{a}}$

\begin{tabular}{lccccc}
\hline Drug & K562 only & $\begin{array}{c}\text { K562/ADM } \\
\text { negative control siRNA }\end{array}$ & $\begin{array}{c}\text { K562/ADM } \\
\text { siRNA MDR }\end{array}$ & $\begin{array}{c}\text { K562/ADM } \\
\text { siRNA MRP1 }\end{array}$ & $\begin{array}{c}\text { K562/ADM } \\
\text { siRNA BCL-2 }\end{array}$ \\
\hline Etoposide & $49.8 \pm 6.15^{\text {b }}$ & $195.3 \pm 8.74$ & $205.4 \pm 13.9$ & $208.4 \pm 0.330$ & $198 \pm 4.64$ \\
\hline
\end{tabular}

${ }^{\mathrm{a}} \mathrm{K} 562$ cells were treated in parallel without prior silencing of MDR genes. There was no significant difference between the $\mathrm{IC}_{50}$ values of each MDR gene knockdown relative to the negative control silencing. The $\mathrm{IC}_{50}$ value of $\mathrm{K} 562$ cells treated with etoposide was significantly lower to that of K562/ADM with MDR gene knockdowns. Values represent the means \pm standard deviation. ${ }^{b} \mathrm{P}<0.05$ vs. siRNA transfectants. $\mathrm{IC}_{50}$, half maximal inhibitory concentration; K562, parental sensitive chronic myeloid leukaemia cell line; K562/ADM, adriamycin-resistant chronic myeloid leukaemia cell line; MDR, multidrug resistant; MDR1, multidrug resistant 1 protein; MRP1, MDR-associated protein 1; BCL-2, B-cell lymphoma 2; siRNA, small interfering RNA.

A

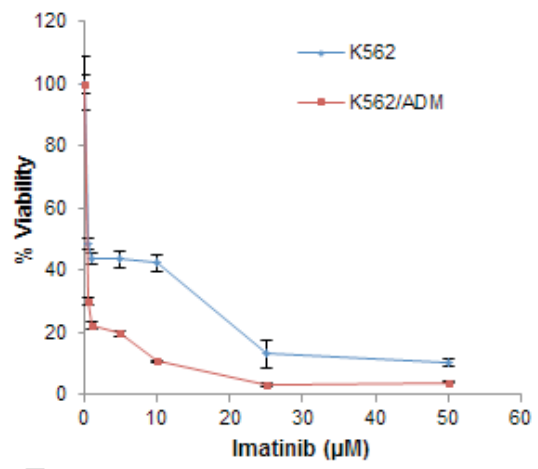

B

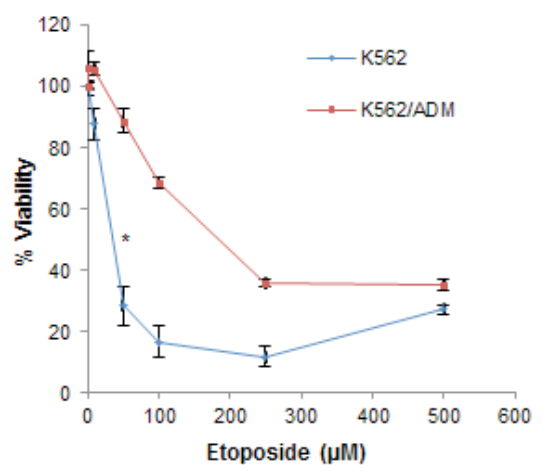

Figure 2. Growth curves of K562 cell lines as determined by an MTS assay (A) Cell lines were treated with $0-50 \mu \mathrm{M}$ imatinib mesylate for a period of $48 \mathrm{~h}$. (B) Cell lines were treated with $0-500 \mu \mathrm{M}$ etoposide for $48 \mathrm{~h}$. Values represent the mean \pm standard deviation. ${ }^{*} \mathrm{P}<0.05, \mathrm{IC}_{50}$ of $\mathrm{K} 562$ cells (50.6 \pm 16.5$)$ vs. K562/ADM (194 \pm 8.46$)$ cells when treated with etoposide. K562, parental sensitive chronic myeloid leukaemia cell line; K562/ADM, adriamycin-resistant chronic myeloid leukaemia cell line.

detect and quantify the rate of apoptosis in parental sensitive K562 and K562/ADM cells following treatment with imatinib mesylate or etoposide (Fig. 4A and B). A large proportion of apoptotic cells were observed in the parental sensitive K562 and $\mathrm{K} 562 / \mathrm{ADM}$ cells treated with imatinib mesylate $(0.5 \mu \mathrm{M})$ for $48 \mathrm{~h}$ (Fig. 4C; $29.3 \pm 6.68$ and $31.9 \pm 16.7 \%$, respectively, $\mathrm{P}>0.05$ ) relative to etoposide $(18.3 \pm 8.35 \%$ in K562 cells and $5.17 \pm 3.3 \%$ in $\mathrm{K} 562 / \mathrm{ADM}$ cells, $\mathrm{P}<0.05$ ), suggesting that the higher expression levels of MDR1 and/or BCL-2 mRNA in K562/ADM cells did not inhibit the apoptosis-inducing effects of imatinib mesylate. By contrast, only the parental sensitive K562 exhibited

\section{A}

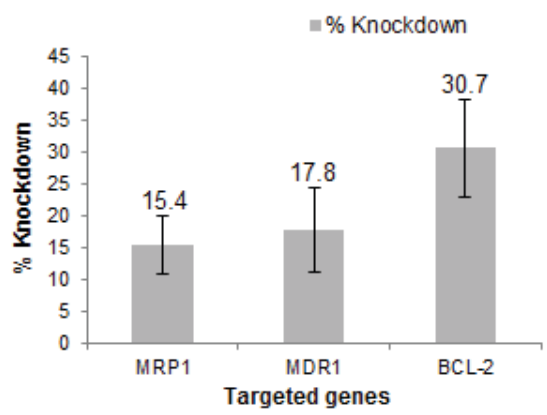

B

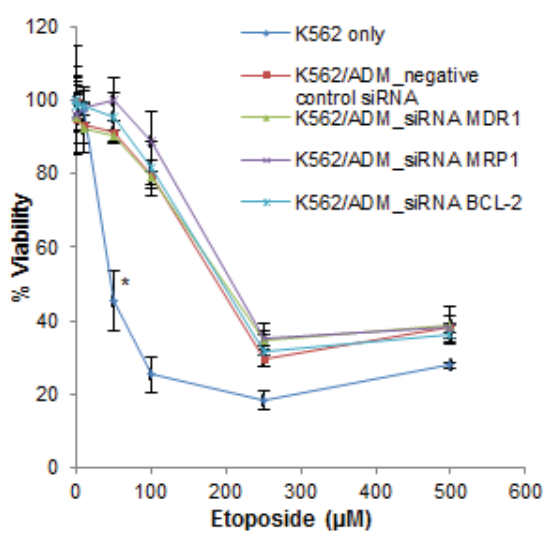

Figure 3. siRNA knockdown of MDR genes followed by an MTS assay (A) Percentage knockdowns of individual MDR genes. There were no significant differences in the relative levels of gene knockdown. (B) The growth curves of K562/ADM cells with individual MDR gene knockdowns following etoposide treatment were similar to the negative control siRNA transfectants. The half maximal inhibitory concentration value for etoposide-treated K562 cells was significantly lower than that observed for MDR siRNA K562/ADM cells (Table II). "P<0.05 vs. siRNA-treated K562/ADM cells. siRNA, small interfering RNA; MDR, multidrug resistance; K562, parental sensitive chronic myeloid leukaemia cell line; K562/ADM, adriamycin-resistant chronic myeloid leukaemia cell line.

a significantly higher percentage of apoptotic cells $(18.3 \pm 8.35 \%)$ when treated with etoposide $(50 \mu \mathrm{M})$ for $48 \mathrm{~h}$ (Fig. $4 \mathrm{C})$ compared with $\mathrm{K} 562$ cells treated for $24 \mathrm{~h}(4.72 \pm 6.23 \% ; \mathrm{P}<0.05)$ and relative to K562/ADM treated with etoposide $(3.27 \pm 2.69 \%$ for $24 \mathrm{~h}$ and $5.17 \pm 3.3 \%$ for $48 \mathrm{~h}$, both $\mathrm{P}>0.05$ ), indicating that the higher levels of MDR1 and/or BCL-2 mRNA in K562/ADM cells may contribute to the resistance of these cells to etoposide. 
A

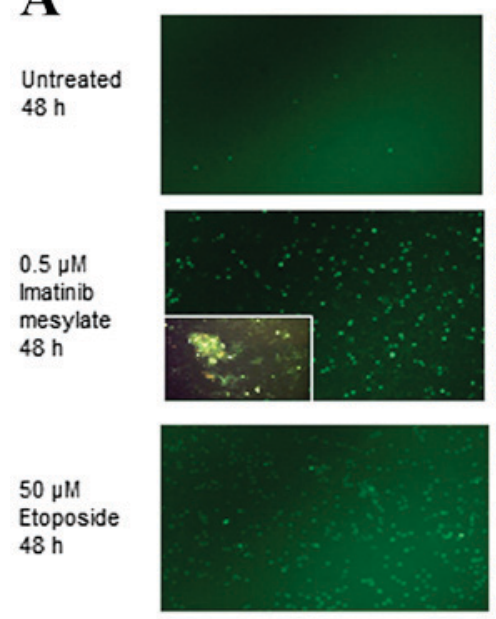

B

Untreated

$48 \mathrm{~h}$
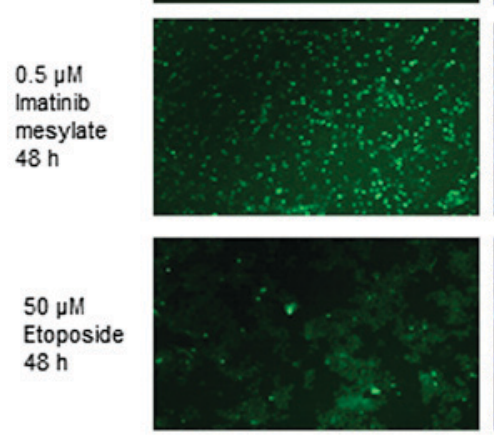

DAPI
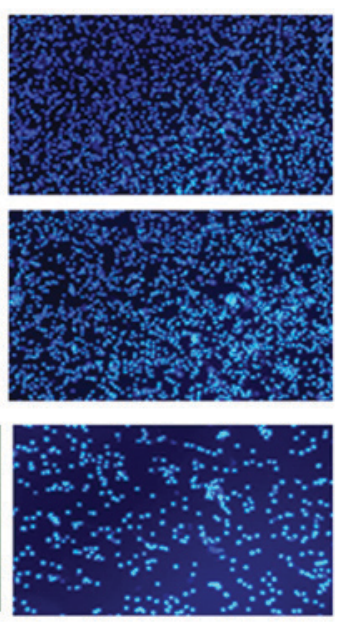

DAPI
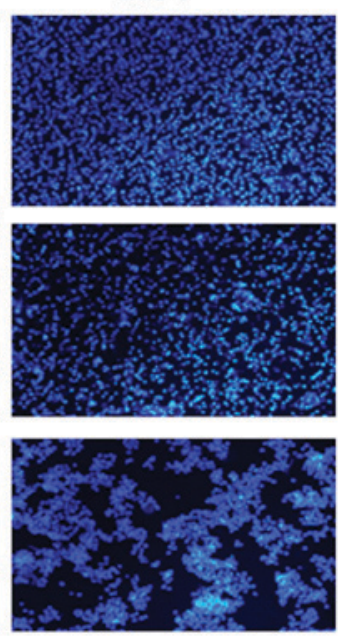

Merged
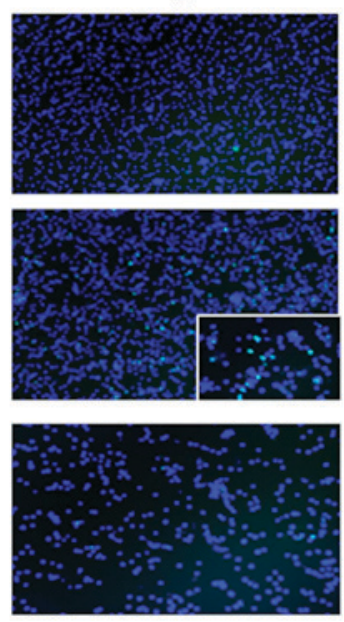

Merged
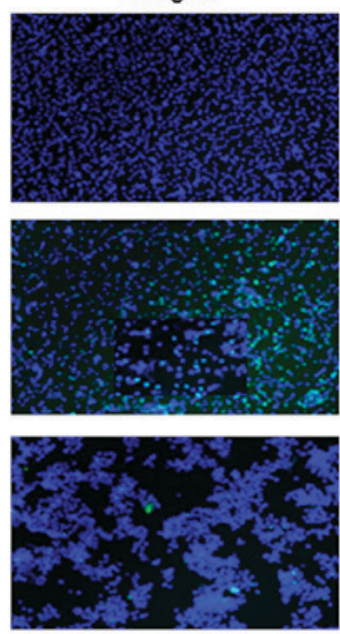

$\mathrm{C}$

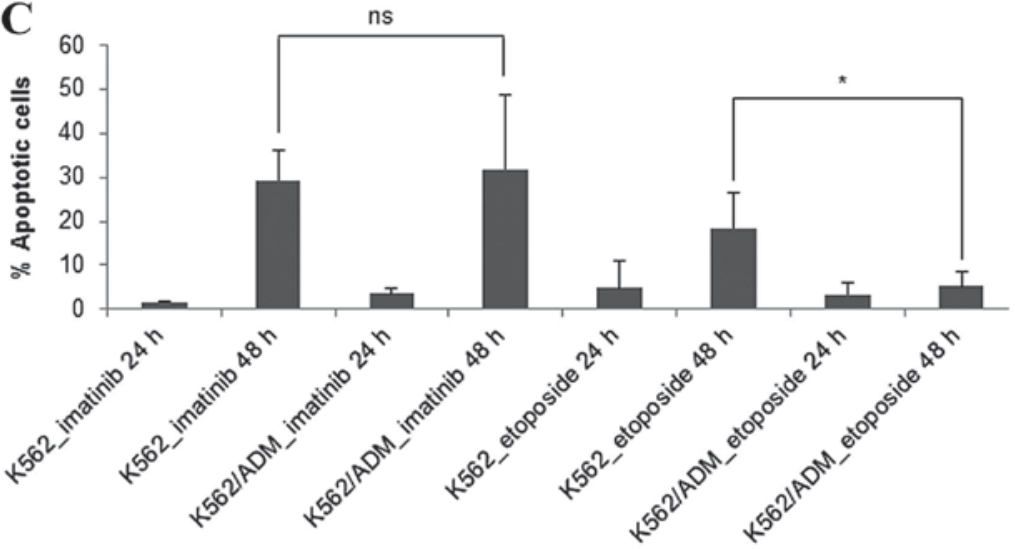

Figure 4. Apoptotic rate of K562 cell lines following imatinib mesylate or etoposide treatment, as detemined by a terminal deoxynucleotidyl transferase dUTP nick end labeling assay. The fluorescent images of (A) apoptotic K562 cells and (B) apoptotic K562/ADM cells were obtained following treatment with $0.5 \mu \mathrm{M}$ imatinib mesylate or $50 \mu \mathrm{M}$ etoposide $48 \mathrm{~h}$. Co-fluorescent cell nuclei (blue DAPI stain) and damaged DNA (green fluorescein isothiocyanate stain) indicated apoptotic cells. Representative images of $\geq 2$ independent experiments are presented. Magnification, $x 100$; insert magnification, $x 400$. (C) Apoptotic cells were counted and their percentage determined. Values represent the mean \pm standard deviation. ${ }^{*} \mathrm{P}<0.05$; not significant (ns) $\mathrm{P}>0.05$. K562, parental sensitive chronic myeloid leukaemia cell line; K562/ADM, adriamycin-resistant chronic myeloid leukaemia cell line; FITC, fluorescein isothiocyanate.

\section{Discussion}

BCL-2 is an anti-apoptotic gene that is involved in the inhibition of apoptotic cell death. The gene is a member of the BCL-2 family, which collectively regulates apoptosis via the promotion or inhibition of apoptosis, through pro-apoptotic
(BAX, Bcl-2 homologous killer and BCL-2 homology domain 3 interacting-domain) or anti-apoptotic (BCL-2, BCL-extra large and induced myeloid leukaemia cell differentiation protein) genes, respectively $(13,48)$ BCL-2 acts by binding to BAX, which inhibits the release of cytochrome $\mathrm{c}$ from the mitochondria. This prevents activation of the caspase 
cascade, thus inhibiting apoptosis $(49,50)$. In the present study, the level of BCL-2 expression was found to be increased in K562/ADM cells relative to parental sensitive K562 cells ( $\sim 6$-fold increase), suggesting that BCL-2 overexpression is responsible for the resistance of K562/ADM cells to etoposide. Furthermore, the etoposide-treated parental sensitive K562 cells underwent a greater rate of apoptosis and had a significantly lower $\mathrm{IC}_{50}$ relative to $\mathrm{K} 562 / \mathrm{ADM}$ cells. This suggests that the increased expression of MDR1 and/or BCL-2 genes in K562/ADM cells may inhibit the cytotoxic action of etoposide, therefore enabling the cells to develop chemoresistance to the drug.

The K562 and K562/ADM cells were sensitive to imatinib mesylate, regardless of the increased MDR gene expression levels in K562/ADM cells, indicating that the MDR genes were unable to inhibit the specific effects of imatinib mesylate. This is in accordance with the TUNEL assay results, whereby imatinib mesylate treatment resulted in a higher number of apoptotic cells for the parental sensitive and adriamycin-resistant K562 cells.

As the parental sensitive K562 and K562/ADM cell lines contain a mutant p53 gene (51), this indicates the chemoresistance of K562/ADM cells to etoposide is not due to the expression of mutant $\mathrm{p} 53$, and thus reiterates the likely involvement of increased MDR1 and/or anti-apoptotic BCL-2 expression. However, cancer cell chemoresistance may be attributed to a number of alternative factors that warrant further study. In accordance with the present findings, results from previous studies suggest that chemoresistant cells have high levels of MDR1 and BCL-2 expression and that this contributes to the MDR phenotype $(13,18,24,48,52)$. Furthermore, inhibition of apoptosis is an established mechanism of chemoresistance in cancer cells $(53,54)$.

A number of techniques, including antisense oligonucleotides, small molecule/peptide inhibitors and monoclonal antibodies, may be used to inhibit the activities of MDR genes. In the present study, the novel method of RNAi silencing (29-31) was performed in order to inhibit the activity of targeted MDR genes, with the aim of sensitising K562/ADM cells to the cytotoxic effects of etoposide However, the RNAi knockdowns exhibited little efficacy in K562/ADM cell sensitization. This may be due to the low efficiency of the MDR gene knockdowns, and/or possibly that the selected MDR genes were not the sole cause of the MDR phenotype in the cells studied. Therefore, potential novel MDR factors other than those already discussed warrant further investigation. Nevertheless, it is necessary to experiment with different transfection reagents or methods, including the key techniques of amaxa nucleofection and electrophoration, in order to increase the efficacy of gene knockdown. Furthermore, cells must be provided with conditions of minimal toxicity to cells prior to MDR gene silencing and chemotherapeutic drug treatments.

In conclusion, imatinib mesylate was effective at stimulating apoptosis in parental sensitive and adriamycin-resistant K562 cells. It was also observed that K562/ADM cells were resistant to etoposide ( $\mathrm{IC}_{50}$ values $194 \pm 8.46 \mu \mathrm{M}$ for K562/ADM cells vs. $50.6 \pm 16.5 \mu \mathrm{M}$ for $\mathrm{K} 562$ cells, $\mathrm{P}<0.05$ ), and had a lower rate of apoptosis relative to parental sensitive K562 cells upon treatment with etoposide. The results indicate that the use of imatinib may be preferable over the use of etoposide in the treatment of CML.

\section{Acknowledgements}

The present study was supported by the Ministry of Health, Malaysia (grant no. JPP-IMR 11-039).

\section{References}

1. National Cancer Institute (NCI). General Information About Chronic Myelogenous Leukemia. https://www.cancer. gov/types/leukemia/patient/cml-treatment-pdq. Accessed January 1, 2017.

2. Cancer Net Leukemia-Chronic Myeloid-CML: Statistics.http://www. cancer.net/cancer-types/leukemia-chronic-myeloid-cml/statistics. Accessed January 1, 2017.

3. Rowley JD: Letter: A new consistent chromosomal abnormality in chronic myelogenous leukaemia identified by quinacrine fluorescence and Giemsa staining. Nature 243: 290-293, 1973.

4. An X, Tiwari AK, Sun Y, Ding PR, Ashby CR Jr and Chen ZS: BCR-ABL tyrosine kinase inhibitors in the treatment of Philadelphia chromosome positive chronic myeloid leukemia: A review. Leuk Res 34: 1255-1268, 2010.

5. Lugo TG, Pendergast AM, Muller AJ and Witte ON: Tyrosine kinase activity and transformation potency of bcr-abl oncogene products. Science 247: 1079-1082, 1990.

6. Shet AS, Jahagirdar BN and Verfaillie CM: Chronic myelogenous leukemia: Mechanisms underlying disease progression. Leukemia 16: 1402-1411, 2002.

7. Mauro MJ and Druker BJ: STI571: Targeting BCR-ABL as therapy for CML. Oncologist 6: 233-238, 2001.

8. Capdeville R, Buchdunger E, Zimmermann J and Matter A: Glivec (STI571, imatinib), a rationally developed, targeted anticancer drug. Nat Rev Drug Discov 1: 493-502, 2002.

9. Savage DG and Antman KH: Imatinib mesylate-a new oral targeted therapy. N Engl J Med 346: 683-693, 2002.

10. Deininger MW and Druker BJ: Specific targeted therapy of chronic myelogenous leukemia with imatinib. Pharmacol Rev 55: 401-423, 2003.

11. Deininger M, Buchdunger E and Druker BJ: The development of imatinib as a therapeutic agent for chronic myeloid leukemia. Blood 105: 2640-2653, 2005.

12. Nooter $\mathrm{K}$ and Herweijer $\mathrm{H}$ : Multidrug resistance (mdr) genes in human cancer. Br J Cancer 63: 663-669, 1991.

13. Stavrovskaya AA: Cellular mechanisms of multidrug resistance of tumor cells. Biochemistry 65: 95-106, 2000.

14. Bush JA and Li G: Cancer chemoresistance: The relationship between p53 and multidrug transporters. Int J Cancer 98: 323-330, 2002.

15. Illmer T, Schaich M, Platzbecker U, Freiberg-Richter J, Oelschlägel U, von Bonin M, Pursche S, Bergemann T, Ehninger $\mathrm{G}$ and Schleyer E: P-glycoprotein-mediated drug efflux is a resistance mechanism of chronic myelogenous leukemia cells to treatment with imatinib mesylate. Leukemia 18: 401-408, 2004.

16. Longley DB and Johnston PG: Molecular mechanisms of drug resistance. J Pathol 205: 275-292, 2005.

17. Rumjanek VM, Vidal RS and Maia RC: Multidrug resistance in chronic myeloid leukaemia: How much can we learn from MDR-CML cell lines? Biosci Rep 33: e00081, 2013.

18. Krishna R and Mayer LD: Multidrug resistance (MDR) in cancer. Mechanisms, reversal using modulators of MDR and the role of MDR modulators in influencing the pharmacokinetics of anticancer drugs. Eur J Pharm Sci 11: 265-283, 2000.

19. Cavalcanti GB Jr, Vasconcelos FC, Pinto de Faria G, Scheiner MA, de Almeida Dobbin J, Klumb CE and Maia RC: Coexpression of p53 protein and MDR functional phenotype in leukemias: The predominant association in chronic myeloid leukemia. Cytometry B Clin Cytom 61: 1-8, 2004.

20. Oren $M$ and Rotter V: Mutant p53 gain-of-function in cancer. Cold Spring Harb Perspect Biol 2: a001107, 2010.

21. Ambudkar SV, Dey S, Hrycyna CA, Ramachandra M, Pastan I and Gottesman MM: Biochemical, cellular, and pharmacological aspects of the multidrug transporter. Annu Rev Pharmacol Toxicol 39: 361-398, 1999. 
22. Giles FJ, Kantarjian HM, Cortes J, Thomas DA, Talpaz M, Manshouri T and Albitar M: Multidrug resistance protein expression in chronic myeloid leukemia: Associations and significance. Cancer 86: 805-813, 1999.

23. Gottesman MM, Fojo T and Bates SE: Multidrug resistance in cancer: Role of ATP-dependent transporters. Nat Rev Cancer 2: 48-58, 2002

24. Miyashita T and Reed JC: Bcl-2 oncoprotein blocks chemotherapy-induced apoptosis in a human leukemia cell line. Blood 81: 151-157, 1993.

25. Türk D and Szakács G: Relevance of multidrug resistance in the age of targeted therapy. Curr Opin Drug Discov Devel 12: 246-252, 2009.

26. Sierra JR, Cepero V and Giordano S: Molecular mechanisms of acquired resistance to tyrosine kinase targeted therapy. Mol Cancer 9: 75, 2010.

27. Bourhis J, Goldstein LJ, Riou G, Pastan I, Gottesman MM and Bénard J: Expression of a human multidrug resistance gene in ovarian carcinomas. Cancer Res 49: 5062-5065, 1989.

28. Salmon SE, Grogan TM, Miller T, Scheper R and Dalton WS Prediction of doxorubicin resistance in vitro in myeloma lymphoma, breast cancer by P-glycoprotein staining. J Natl Cancer Inst 81: 696-701, 1989.

29. Ro J, Sahin A, Ro JY, Fritsche H, Hortobagyi G and Blick M: Immunohistochemical analysis of P-glycoprotein expression correlated with chemotherapy resistance in locally advanced breast cancer. Hum Pathol 21: 787-791, 1990.

30. Goldstein LJ, Fojo AT, Ueda K, Crist W, Green A, Brodeur G, Pastan I and Gottesman MM: Expression of the multidrug resistance, MDR1, gene in neuroblastomas. J Clin Oncol 8: 128-136, 1990.

31. Robey-Cafferty SS, Rutledge ML and Bruner JM: Expression of a multidrug resistance gene in esophageal adenocarcinoma. Correlation with response to chemotherapy and comparison with gastric adenocarcinoma. Am J Clin Path 93: 1-7, 1990.

32. Scheper RJ, Broxterman HJ, Scheffer GL, Meijer CJ and Pinedo HM: Drug-transporter proteins in clinical multidrug resistance. Clin Chim Acta 206: 25-32, 1992.

33. Marie JP, Zhou DC, Gurbuxani S, Legrand $\mathrm{O}$ and Zittoun $\mathrm{R}$ : MDR1/P-glycoprotein in haematological neoplasms. Eur J Cancer 32A: 1034-1038, 1996.

34. Thomas A, El Rouby S, Reed JC, Krajewski S, Silber R, Potmesil M and Newcomb EW: Drug-induced apoptosis in B-cell chronic lymphocytic leukemia: Relationship between p53 gene mutation and bcl-2/bax proteins in drug resistance. Oncogene 12 1055-1062, 1996

35. Pepper C, Hoy T and Bentley DP: Bcl-2/Bax ratios in chronic lymphocytic leukaemia and their correlation with in vitro apoptosis and clinical resistance. Br J Cancer 76: 935-938, 1997.

36. Stoetzer OJ, Pogrebniak A, Scholz M, Pelka-Fleischer R, Gullis E, Darsow M, Nüssler V and Wilmanns W: Drug-induced apoptosis in chronic lymphocytic leukemia. Leukemia 13 $1873-1880,1999$.

37. Hannon GJ and Rossi JJ: Unlocking the potential of the human genome with RNA interference. Nature 431: 371-378, 2004.
38. Pai SI, Lin YY, Macaes B, Meneshian A, Hung CF and Wu TC: Prospects of RNA interference therapy for cancer. Gene Ther 13: 464-477, 2006

39. Lage H: Therapeutic potential of RNA interference in drug-resistant cancers. Future Oncol 5: 169-185, 2009.

40. Caplen NJ, Parrish S, Imani F, Fire A and Morgan RA: Specific inhibition of gene expression by small double-stranded RNAs in invertebrate and vertebrate systems. Proc Natl Acad Sci USA 98: 9742-9747, 2001

41. Wu H, Hait WN and Yang JM: Small interfering RNA-induced suppression of MDR1 (P-Glycoprotein) restores sensitivity to multidrug-resistant cancer cells. Cancer Res 63: 1515-1519, 2003.

42. Ando T, Nishimura M and Oka Y: Decitabine (5-Aza-29deoxycytidine) decreased DNA methylation and expression of MDR-1 gene in K562/ADM cells. Leukemia 14: 1915-1920, 2000.

43. Zalcberg J, Hu XF, Slater A, Parisot J, El-Osta S, Kantharidis P, Chou ST and Parkin JD: MRP1 not MDR1 gene expression is the predominant mechanism of acquired multidrug resistance in two prostate carcinoma cell lines. Prostate Cancer Prostatic Dis 3: 66-75, 2000.

44. Wang TT and Phang JM: Effects of estrogen on apoptotic pathways in human breast cancer cell line MCF-7. Cancer Res 55: 2487-2489, 1995

45. Pfaffl MW: Quantification strategies in real-time PCR. In: A-Z of quantitative PCR. Bustin SA (ed). International University Line (IUL), La Jolla, CA, Chaper 3, pp87-112, 2004.

46. Morrison DJ, English MA and Licht JD: WT1 induces apoptosis through transcriptional regulation of the proapoptotic Bcl-2 family member Bak. Cancer Res 65: 8174-8182, 2005.

47. Bolha L, Dušanić D, Narat M and Oven I: Comparison of methods for relative quantitation of gene expression using real-time PCR. Acta Arg Sloven 100: 97-106, 2012.

48. Adams JM and Cory S: The Bcl-2 protein family: Arbiters of cell survival. Science 281: 1322-1326, 1998.

49. Sakahira H, Enari M and Nagata S: Cleavage of CAD inhibitor in CAD activation and DNA degradation during apoptosis. Nature 391: 96-99, 1998.

50. Mihara M, Shintani S, Nakashiro $K$ and Hamakawa $H$ : Flavopiridol, a cyclin dependent kinase (CDK) inhibitor, induces apoptosis by regulating Bcl-x in oral cancer cells. Oral Oncol 39: 49-55, 2003.

51. International Agency for Research on Cancer (IARC). World Health Organisation: IARC p53 database. http://p53.iarc. fr/CellLines.aspx. 2016. Accessed January 1, 2017.

52. Perkins C, Kim CN, Fang G and Bhalla KN: Arsenic induces apoptosis of multidrug-resistant human myeloid leukemia cells that express Bcr-Abl or overexpress MDR, MRP, Bcl-2, or Bcl-x (L). Blood 95: 1014-1022, 2000.

53. Holohan C, Van Schaeybroeck S, Longley DB and Johnston PG: Cancer drug resistance: An evolving paradigm. Nat Rev Cancer 13: 714-726, 2013

54. Housman G, Byler S, Heerboth S, Lapinska K, Longacre M, Snyder N and Sarkar S: Drug resistance in cancer: An overview. Cancers (Basel) 6: 1769-1792, 2014 